\title{
IMERSÃO RECÍPROCA - UM MÉTODO DE ENSINO/APRENDIZAGEM PARA COMUNIDADES BI-/PLURILÍNGUES?
}

Reseda Streb

\begin{abstract}
RESUMO
A imersão recíproca representa um método pedagógico de extrema relevância para comunidades bi-/plurilíngues, tendo como proposta central a igualdade de duas línguas e culturas parceiras. Nosso foco será abordar as seguintes questôes: como é a aplicação deste método na prática? Quais os desafios e as vantagens para o processo de aprendizagem? Estes pontos serão analisados e discutidos neste artigo.
\end{abstract}

PALAVRAS CHAVE: Ensino/aprendizagem bi-/plurilíngüe; repertório bi-/plurilíngue; imersão recíproca.

\section{Introdução}

\begin{abstract}
o abordamos a aprendizagem de língua(s) através da imersão recíproca em ambientes de educação bi-/plurilíngues, precisamos, inicialmente, revisar alguns conceitos, tais como as noçóes de registro, repertório bi-/ plurilíngue e o próprio desenvolvimento de repertórios no processo de aprendizagem. Assim, o ponto de partida da argumentação baseia-se nos dados empíricos da tese de doutorado da autora, cujas informaçóes foram coletadas em um projeto ítalo-alemão em uma escola pública do ensino fundamental em Frankfurt ${ }^{1}$, Alemanha. $\mathrm{O}$ objetivo desta análise é averiguar a possibilidade de inserção vantajosa deste método em outros contextos bi-/plurilíngues.
\end{abstract}

1 Para mais detalhes veja Streb 2015. 


\section{Revisão de conceitos teóricos}

A escola de ensino fundamental busca o preparo dos alunos para sua independência, tanto na vida pessoal quanto na futura vida profissional, e, independentemente da quantidade de idiomas de instrução, a missão é o desenvolvimento global da linguagem escrita. À primeira vista, a alfabetização parece ser o objetivo principal de aprendizado. No entanto, aprender como lidar com a linguagem escrita é mais do que aprender a ler e escrever. O letramento é um processo complexo que vai além da compreensão da relação entre fonema e grafema e das regras ortográficas. Escrever um texto significa identificar um tipo de formato, assim como inserir os elementos adequados. $\mathrm{O}$ letramento vai além dos conhecimentos linguísticos para o meio escrito. $\mathrm{O}$ aluno precisa aprender quais os registros e as regras existentes. É importante diferenciar entre o termo linguagem escrita e o significado do registro formal. Enquanto a linguagem escrita se limita ao meio escrito, o registro formal abrange estruturas complexas independentemente do meio usado. Assim sendo, para entender melhor esta distinção, é necessário especificar a ideia do termo "registro".

Uma perspectiva social para ver os conhecimentos linguísticos de um falante é a divisão dos mesmos conhecimentos em registros. Esta abordagem se orienta em conformidade com o crescimento social do falante, que aumenta com a ampliação das situaçóes sociais do indivíduo. Maas (2005) diferencia entre o registro informal intimo, falado dentro da família; o registro informal público, falado com os amigos e em lugares públicos como no mercado, na rua; e o registro formal público, usado em instituiçóes públicas como a escola e, posteriormente, em outros serviços públicos. O que determina a diferença entre os registros é a função dos mesmos para o falante e a composição dependente. Uma criança pode crescer em Frankfurt numa família italófona, desenvolvendo assim o registro íntimo em italiano. Já na rua e com os amigos terá contato com a língua majoritária, neste caso o alemão, e possivelmente com outras línguas de migração da região, como turco, grego, polonês, entre outros. $\mathrm{Na}$ escola, independentemente das línguas/variedades nos registros íntimo e informal, a criança terá que aprender o registro formal em alemão. Esta condição abrange todas as crianças que crescem em contexto de migração e/ou em famílias que falam uma língua/variedade diferente da língua oficial. Por- 
tanto, a aprendizagem do registro formal pode vir a se tornar um desafio para as crianças crescidas com a língua oficial como primeira língua: neste caso, o contexto social pode determinar o sucesso do aluno na escola. As crianças de contexto social menos favorecido sofrem mais dificuldades por não trazerem conhecimentos no registro formal de casa, e a escola, por sua vez, não é capaz de amparar estes alunos.

O termo do registro ainda tem como objetivo a dissolução da imagem de um falante mono- ou bi-/plurilíngue perfeito, que domine todos os registros e elementos referentes a uma ou mais línguas/variedades. $\mathrm{O}$ registro é determinado através da função social que ele tem para os falantes. A composição do repertório em si pode então nutrir-se de uma ou mais línguas/variedades, como afirma Hélot:

Le répertoire se présente donc comme un ensemble de ressources langagières, qui se manifestent chez le monolingue dans des registres différents tandis que, chez le bilingue, certains éléments de son répertoire appartiennent a une langue A et d'autres à la langue $\mathrm{B}$. Ce répertoire est organisée non pas par l'addition mais por combinaison des différentes langues (ou variétés de langues) possibles. (Hélot, 2007, p. 8)

Se usarmos o termo do registro para diferenciar entre as formas de linguagem de acordo com o contexto social, a noção de repertório deve servir como totalidade de conhecimentos linguísticos. O falante pode ter conhecimento, por exemplo, do registro íntimo em uma língua/variedade, como em italiano; já o próximo registro, em outra língua/variedade, como em alemão. Isto significa que um falante bi-/plurilíngue não se define por ter os mesmos conhecimentos linguísticos nas suas duas ou mais línguas/variedades. A razão disto é que normalmente o contexto social influencia a função e a necessidade de um certo registro em uma língua/uma variedade.

A conclusão teórica e prática desta observação é que não existe um falante que domine perfeitamente todos os registros de uma ou mais línguas. Evidentemente, pode haver falantes que, devido às próprias experiências linguísticas, desenvolvem uma competência avançada em vários registros nas diferentes línguas/variedades. Todavia, é questionável se a escola deve se orientar 
por um falante ideal para o processo de aprendizagem dos alunos. O cenário ideal é quando a escola se adapta à realidade linguística dos próprios alunos, levando assim em consideração os recursos existentes e os objetivos de aprendizagem dos mesmos.

Tendo definido os termos registro e repertório, focaremos em seguida no funcionamento do desenvolvimento / da montagem do repertório bi-/plurilíngue. Blommaert/Backus $(2011)^{2}$ explicam que falar e aprender uma língua como sistema linguístico e sociolinguístico não é um processo cumulativo, é um processo de crescimento, de aprendizagem sequencial de certos registros, estilos, gêneros e variedades linguísticas, enquanto se perde ou altera outros anteriormente existentes.

Para uma descrição e análise mais detalhada desta perspectiva de desenvolvimento/montagem de repertório, Maas criou duas noçôes técnicas artificiais: orat e literat. O conceito orat ${ }^{3}$ define-se por nomear estruturas linguísticas que não são organizadas em orações gramaticais completas e relacionadas a situações concretas, mas não limitadas ao meio da fala. Sabemos que estas mesmas estruturas podem ser usadas também na escrita, como, por exemplo, num chat, num torpedo, ou em qualquer tipo de mensagem do registro íntimo e/ou informal. O termo orat forma um ponto extremo de um contínuo, com o termo literat ${ }^{4}$ ao outro lado. Literat são estruturas tipicamente utilizadas, não limitadas ao meio escrito, e caracterizadas pela expressão de contextos complexos com máxima explicitação. Os termos assim criados descrevem a característica das estruturas linguísticas, sem limitá-las a um certo meio. Voltando ao contexto educativo, o objetivo da escola é o de ensinar aos alunos o domínio das estruturas do tipo literat. Como será a situação do aprendiz quando há mais de uma língua/variedade envolvida?

2 "to speak and learning language as a linguistic and a sociolinguistic system is not a cumulative process; it is rather a process of growth, of sequential learning of certain registers, styles, genres and linguistic varieties while sheddering or altering previously existing ones" (Blommeart/Backus, 2011, p. 9).

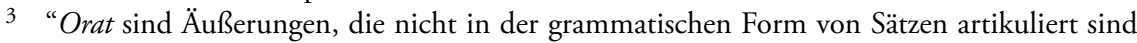
und ggf. sprachliche Elemente aufweisen, die auf konkrete Sprachsituationen kalibriert sind" (Maas, 2010, p. 98)

4 "Literat ist die Dimension des maximalen Verfügens über die Strukturpotentiale der Sprache, deren Nutzen für die Explikation (Entfaltung) eines Sachverhalts, für dessen Repräsentation" (Maas, 2008, p. 330) 
A escola tem que tomar em conta todos os recursos linguísticos que os alunos trazem e prepará-los para o uso do registro formal em todas as línguas que serão necessárias para eles. Uma forma de poder tomar em consideração os recursos de pelo menos duas línguas/culturas é a imersão recíproca, que será discutida na segunda parte do artigo.

\section{A formação do método}

A dupla imersão (imersão recíproca) é um conceito de ensino que permite uma aprendizagem bilíngue por meio de aprendizagem de duas línguas e em duas línguas. A primeira escola a oferecer um programa bilíngue espanhol-inglês abriu em 1963 em Miami (Coral Way Elementary; Pérez, 2004, Potowski, 2007). A iniciativa deste primeiro projeto partiu de um grupo de cubanos refugiados, que almejou manter as competências dos filhos em espanhol para um possível retorno ao seu país. Hoje em dia existem, segundo o Center for Applied Linguistics ${ }^{5}$, somente nos EUA, 458 escolas que oferecem um ensino bilíngue deste tipo. Só em New York se encontram, entre outras, modelos com espanhol, francês, chinês (García, 2009). Para os alunos de língua minoritária, estes programas representam uma valorização da própria língua fora da família, e, para os alunos de língua majoritária, o ensino bilíngue possibilita construir competências profundas em mais de uma língua. No que tange ao segmento social, os programas favorecem o encontro de dois grupos linguístico-culturais, incluindo também as famílias e as comunidades nas atividades escolares.

A ideia da imersão recíproca nasceu dos resultados positivos dos programas canadenses de imersão unilateral nos anos 1960. Estes programas mostraram que o uso da língua alvo como língua de instrução alcança resultados melhores na aprendizagem de língua do que métodos tradicionais. A imersão unilateral foi criada pela população anglófona na província canadense Quebéc, para que as crianças da minoria anglófona recebessem a educação escolar na língua francesa (Heller, 1999, Budach/Erfurt/Kunkel, 2008).

5 http://www2.cal.org/jsp/TWI/SchoolListings.jsp, 15.10.2015. Esta lista não toma em consideração as escolas que realizam a prática da imersão recíproca de forma modificada ou com menos de cinco anos de duração. Adicionais a este lista, existem muitas escolas com conceitos mais ou menos divergentes da imersão recíproca. 
A imersão recíproca se diferencia da unilateral por incluir duas línguas e duas culturas no processo de ensino/aprendizagem. O objetivo da igualdade das duas línguas/culturas é a base fundamental do método, tanto na valorização linguística quanto na social.

Em Frankfurt, Alemanha, a iniciativa também partiu de famílias com origem migratória. Por meio da sua condução nas negociações diplomáticas, iniciou-se a abertura de projetos bilíngues em escolas públicas (francês, espanhol, inglês, italiano). Depois da Segunda Guerra Mundial, a Alemanha fez acordos com Grécia, Itália, entre outros, para aumentar a força trabalhadora do país. Com o passar dos anos, estes trabalhadores traziam as famílias do país de origem ou fundavam famílias na Alemanha, mudando assim a própria perspectiva de retornar ao país natal. Esta mudança de perspectiva salientou a vontade e necessidade de que os filhos de imigrantes mantivessem o contato com a língua e cultura dos pais. Assim, em 1995, um grupo de pais de descendência italiana iniciou o processo de negociação com o consulado geral italiano em Frankfurt, o estado Hessen e o Ministério de Educação da cidade de Frankfurt.

A primeira escola bílingue ítalo-alemã (ensino fundamental, anos 1 a 4) foi aberta em 1997. Desde então, mais quatro escolas confirmaram a colaboração para um ensino bilíngue ítalo-alemão: três escolas de ensino fundamental (anos 1 a 4), uma escola de ensino médio (anos 5 a 10) e uma escola de ensino médio que inclui o Abitur (anos 5 a 12) ${ }^{6}$. A escola que é abordada neste estudo específico chama-se Holzhausenschule, escola de ensino fundamental, que, desde 2003, oferece a imersão recíproca ítalo-alemã para uma turma por ano letivo ${ }^{7}$.

\section{Os princípios do método}

O objetivo principal da imersão recíproca é a igualdade entre as duas línguas parceiras no processo de aprendizagem em geral. Dois fatores precisam ser alinhados para alcançar este alvo. O primeiro é o uso dos dois idiomas como língua de instrução em sala de aula, e o segundo é a composição da turma.

6 O sistema educativo na Alemanha prevê nove anos obrigatórios de escola, mais três a quatro anos de livre escolha. $\mathrm{O}$ ensino é estruturado em quatro anos de ensino fundamental: anos 1 a 4; seis anos de ensino médio: anos 5 a 10; e mais 2 a 3 anos para conseguir o Abitur, uma prova final que é comparável com o Enem e que pode dar acesso ao ensino superior.

7 Para uma documentação sobre a primeira turma bilíngue desta escola, veja Budach (2011). 
A distribuição igual das duas línguas parceiras nas aulas é um dos dois pilares do método e pode ser realizada por intermédio de um professor ou de uma dupla de professores bilíngues. Todas as disciplinas e todas as matérias devem ser ensinadas nas duas línguas para conseguir um equilíbrio de status entre as duas línguas parceiras. $\mathrm{O}$ ensino do conteúdo em duas línguas não significa o duplo ensino, mas dois recursos diferentes dentro da sala de aula. $\mathrm{Na}$ versão de um professor bilíngue, ele/a pode estruturar a distribuição de línguas ao longo do dia, entre as disciplinas ou matérias, sempre mantendo o mesmo valor para cada língua. Muitas escolas também fazem questão de que cada língua tenha uma própria sala para a separação mais clara. Como visto na revisão das noçóes acima, esta separação de línguas não é necessária. Pelo contrário, ela pode impedir o livre acesso dos alunos aos próprios recursos linguísticos, como será discutido nas formas de aulas da imersão recíproca logo abaixo. Uma outra forma de distribuir as duas línguas parceiras de maneira igual é por meio de uma dupla de professores, na qual cada um dos deles represente uma das duas línguas. O team-teaching segue neste caso o princípio "uma pessoa - uma língua" (Une personne - une langue, Ronjat 2014). De acordo com este princípio, as aulas por si são bilíngues, mas cada professor torna-se o exemplo de um falante monolíngue de uma das duas línguas. Uma desvantagem do ensino em dupla é o aumento do tempo de planejamento das aulas. A dupla precisa planejar a liderança para cada momento, assim como desenvolver e coordenar o material a ser apresentado, etc.

A composição da turma, o segundo pilar da imersão recíproca, deve representar as duas línguas/culturas parceiras da mesma forma. Metade dos alunos vem de famílias de uma língua/cultura, metade da outra. Entende-se facilmente que entre os dois grupos haverá alunos que fazem parte de ambas as línguas/culturas, porque vêm de famílias bi-/plurilíngues. As competências linguísticas dentro dos grupos podem variar amplamente. No caso da turma observada em Frankfurt, todos os alunos trazem conhecimentos em alemão, mas uma metade vem de famílias com contato com a língua italiana. Este contato pode ser descrito por intensidades diferentes, com alguns alunos tendo dois pais que falam italiano, ou até uma avó ou avô que fale italiano com os netos. Devido a este fato, as crianças trazem conhecimentos diferentes da língua italiana (também pode-se tratar de conhecimentos de uma variedade regional em vez do italiano standard). 


\section{Desafios e vantagens na prática em frankfurt}

Veremos agora os desafios e as vantagens da imersão recíproca que foi observada na turma em Frankfurt. $\mathrm{O}$ foco estará na negociação de status entre as duas línguas parceiras durante as aulas, como também no desenvolvimento do registro formal dos alunos.

No caso da turma ítalo-alemã em Frankfur,t existem duas professoras que formam um time para o team-teaching. Enquanto a professora responsável pelo alemão não fala italiano, salvo algumas expressóes ou alguns termos técnicos de aula, a professora responsável pelo italiano acabou de chegar da Itália com um alemão bem básico. Quem olha para esta dupla pode suspeitar problemas de comunicação entre as duas professoras e temer que não será fácil ensinar neste time. A prática em Frankfurt mostrou que, mesmo com estas competências, é possível dar conta de aulas bilíngues. Um fator interessante é que, neste caso, as duas professoras também se tornaram aprendizes da outra língua parceira, mostrando interesse em aprendê-la e a aprendendo de verdade.

A turma observada nos anos de 2008 a 2012 é constituída de 25 alunos. Metade da turma vem de famílias sem conhecimento de italiano, enquanto a outra metade tem pelo menos um familiar com o qual tem contato com a língua italiana. Isto significa que o conhecimento dos alunos em italiano varia de conhecimento básico ou passivo a registros íntimos e informais desenvolvidos. Todos os alunos vêm para a escola com competências em alemão, alguns têm também conhecimento de albanês, francês, inglês ou espanhol. A partir do primeiro dia, as crianças recebem as instruçóes de todas as matérias e a alfabetização em ambas as línguas, italiano e alemão. O objetivo é proporcionar aos alunos com repertórios diferentes um desenvolvimento do registro formal nas duas línguas parceiras, exigindo assim vários tipos de aulas e diferentes "ofertas de aprendizagem” (veja Ausbauangebote em Streb, 2015), tanto monolíngues como bilíngues.

García (2009a, b) aconselha que os professores liberem a prática do translanguaging durante as aulas que não se concentram no ensino de línguas. Isto signifyica que, nestes momentos, o foco da atenção estará no conteúdo, e não na escolha de uma certa língua. $\mathrm{O}$ exemplo seguinte da turma em Frankfurt mostra que esta forma de aula funciona. $\mathrm{O}$ aluno Michele passou seus primeiros cinco anos na Itália, e depois a sua família mudou-se para a 
Alemanha, onde ele entrou no ensino fundamental com seis anos de idade e tendo um ano de aprendizagem do alemão do jardim de infância ${ }^{8}$. O exemplo mostra a comunicação de Michele na sala de aula com duas professoras, cada uma representando a própria língua parceira.

52 Bianchi: alloRa; adesso sentiamo un maschio, michele;

53 Michele: solo in italiano;

54 Bianchi: va bene; solo, nur auf italienisch, okay,

55 Schmidt: echt? warum nicht auf deutsch? bist du unsicher?

56 Michele: $j a$; weil ich glaub ich hab was vergessen;

57 Schmidt: is okay;

58 Bianchi: va bene; dai; ${ }^{9}$

Nesta aula, de assuntos biológico-geográficos, as duas professoras estão presentes. A professora do italiano, Signora Bianchi, está escolhendo o próximo aluno para ler os textos escritos em casa e escolhe Michele. Michele responde em italiano que ele vai ler só o texto escrito em italiano. Signora Bianchi concorda com ele em italiano, mas, para incluir a professora de alemão, que não pode acompanhar a conversa em italiano, repete em alemão a própria resposta. Agora, Frau Schmidt, pergunta em alemão a Michele porque ele não quer ler o texto em alemão, supondo que ele esteja inseguro. Michele, que até agora tinha falado somente em italiano com Signora Bianchi, responde em alemão à Frau Schmidt que sim, ele acredita que tenha esquecido de algo. Frau Schmidt então confirma em alemão que está de acordo. Signora Bianchi confirma em italiano e pede que o aluno comece a ler.

Esta cena mostra uma certa naturalidade com a qual o aluno Michele troca as línguas como recurso, respondendo sempre na língua de responsabilidade das professoras. Esta estrutura de comunicação é uma consequência do princípio "uma pessoa, uma língua" que as professoras seguem neste projeto. Ao mesmo tempo, mostra a capacidade do aluno de usar os recursos nas duas línguas. Nesta

8 O jardim da infância na Alemanha é uma instituição pública para crianças de aprox. 4 a 6 anos. Ao contrário dos anos obrigatórios da escola, o jardim da infância é voluntário.

9 Tradução. Bianchi: então; agora escutamos um menino, michele; Michele: só em italiano; Bianchi: tudo bem; só, só em italiano, okay, Schmidt: é mesmo? por que não em alemão? você está inseguro? Michele: estou; porque acho que eu esqueci de algo; Schmidt: está tudo bem; Bianchi: tudo bem, vai; (FB-K4: 07.12.2011). 
sequência, as professoras permitiram ao aluno ler somente o texto em sua língua mais segura. Lendo bem a conversa entre eles, pode-se suspeitar que a razão pela qual Michele não queira ler o texto alemão não seja a insegurança do aluno em relação a esse idioma, mas o fato de que ele tenha esquecido de escrever uma parte. De qualquer forma, a imersão recíproca possibilita a Michele que ele use a sua língua de família - sendo a minoritária neste caso - num contexto institucional, dando, desta forma, valor à língua e à autoestima do aluno.

A turma bilíngue pode ser usada como recurso pelos professores. Este é o caso do próximo exemplo, com o aluno Marco, no terceiro ano. Ele vem de uma família italófona, mas o seu repertório não inclui a palavra "Filzstifte" (pt. caneta de feltro) em italiano. Assim, Signora Bianchi recorre aos recursos de um outro aluno para encontrar a palavra procurada.

Marco: possiamo coloRaRe anche con filzstifte?

Bianchi: sì; si puo coloRaRe anche con?

Ricardo: pennaRelli;

Bianchi: con i pennaRelli; bRavo RicaRdo; ${ }^{10}$

Além de poder usar a turma bilíngue como recurso para a aula, esta cena mostra também como os alunos recorrem aos seus recursos bi-/plurlíngues para se expressarem. Marco não lembrou a palavra "Filzstifte" em italiano, mas teve acesso a esta palavra em alemão.

A troca de língua para palavras ou expressóes soltas pelos falantes é também uma técnica que as professoras usam no contexto da aprendizagem de língua. Signora Bianchi, por exemplo, assegura desta forma que todos os alunos - independentemente das línguas faladas em família - possam acompanhar o raciocínio da lição. A professora conhece bem o repertório não só da turma, mas de cada aluno, e sabe qual é o momento de introduzir uma palavra nas duas línguas: "Bianchi: (...) ha venduto, un, vestito; (-) venduto è verkauft, ha venduto un vestito; lena" ${ }^{11}$.

10 Trad. Marco: podemos desenhar também com as canetas de feltro? Bianchi: sim, podemos desenhar com as? Ricardo: canetas de feltro; Bianchi: com as canetas de feltro, muito bem Ricardo (FB-K3: 01.12.2010)

11 Trad. (...) vendeu, um, vestido; (-) vendeu significa vendeu vendeu um vestido; lena (FBK4: 25.10.2011). 
Esta troca de língua também pode ser usada para organizar a própria fala em dois níveis diferentes, por exemplo, quando Signora Bianchi quer assegurar que todos tenham entendido a tarefa de casa: "Bianchi: maRco mangia la mela; dann? (--) questo bambino; cosa fa? sch:: alle müssen aufpassen; das ist die hausaufgabe, es ist WICHTIG; (-) laRa, cosa fa questo bambino?"12.

O uso do "translanguaging" pela professora mostra-se aqui também, como descrito por García, para conseguir a atenção dos alunos. O uso das partes em alemão (em itálico) se refere às partes organizatórias da fala da professora, para pedir aos alunos mais atenção, já que se trata de uma informação importante, pois será o exercício de casa. As partes ditas em italiano, ao invés do alemão, referem-se à própria tarefa, dando exemplos de como o aluno terá que resolvê-la.

Pela observação das aulas, foi possível distingui-las em dois modos: o bilíngue, como demonstraram os exemplos acima citados, e o monolíngue, no qual as professoras tentam convencer os alunos a usar somente uma língua como meio de comunicação. $\mathrm{O}$ modo monolíngue pode ser considerado como preparação para o uso do registro formal, que normalmente proíbe a assim chamada "mistura" de línguas ou que, por causa de um público maior de falantes, tende a limitar-se a um só idioma. Grosjean (2012) não limita estas observaçôes sobre falantes bi-/plurilíngues ao contexto escolar. Ele descreve como o falante bi-/plurilíngue precisa adaptar o próprio acesso as suas línguas, que se encontram num contínuo de ser livremente bilíngue a completamente monolíngue.

Bilinguals in their everyday lives find themselves in various language modes that correspond to points on a monolingualbilingual mode continuum. At one ende of the continuum, bilinguals find themselves in a bilingual langauge mode in that they are communicating with (or listeing to) bilinguals who share two (or more) languages and with whom code-switching and borrowing may take place. At the other end of the continuum, bilinguals are in a monolingual language mode in that they are interacting only with (or listening only to) monolinguals of one or the other - of the languages they know. (Grosjean, 2012, p. 12).

12 Trad. Marco come a maçã, depois? (--) esta criança; o que faz? sch:: todos devem prestar atençâo; isto será a tarefa de casa, é IMPORTANTE; (-) Lara, o que faz esta criança? (FB-K2: 24.02.2010). 
A imersão recíproca toma em consideração ambos os extremos do contínuo: o modo monolíngue em cada uma das línguas, como preparo às situaçóes formais, e o modo bilíngüe, em que todos os recursos são valorizados e permitidos para discutir um conteúdo determinado.

Um método que se baseia nos conhecimentos variados dos alunos é o trabalho em "tandem". Dois alunos de conhecimentos diferentes em italiano e alemão devem trabalhar juntos, ajudando=se e resolvendo a tarefa em equipe. Desta forma, os dois alunos podem sentir que as duas línguas têm um papel importante na aula e assim colaboram para a estabilidade do status igualitário das línguas parceiras. Especialmente nesta forma de trabalho dos alunos destaca-se uma outra vantagem da imersáo recíproca: os alunos podem orientar-se na aprendizagem de língua não somente pelos professores, mas também por falantes da mesma idade, com o uso de línguagem típica e limitada a certas idades.

Um outro desafio a ser superado pelas professoras é o de encontrar material didático adequado. Em muitos casos, não só em Frankfurt, o material usado nas aulas segue o currículo da língua nacional/majoritária. Assim, o professor responsável pela língua minoritária sofre uma perda de status, e, além disto, é obrigado a criar próprios materiais para poder acompanhar o conteúdo das aulas ${ }^{13}$.

Uma parte da elaboração do registro formal nutre-se de termos técnicos. Estes estão presentes em todas as disciplinas, como, por exemplo, na matemática (it. parallelepipedo, all. Quader, pt. paralelepipedo). Além de aprender termos técnicos, os alunos precisam aprender a diferenciar entre os registros diferentes (tanto na escrita como na fala) as características e restriçóes específicas que cada gênero textual pede. Um gênero muito usado na educação fundamental é o da narração de contos. Narrando uma história, os alunos precisam conhecer as fórmulas de introdução e de finalização; precisam apresentar os personagens de uma forma que o leitor/ouvinte possa seguir as açôes da história; precisam variar os conectores, etc. $\mathrm{Na}$ análise mais concreta de um texto escrito por alunos, nota-se que o conhecimento do registro formal exige do aluno um conhecimento específico da língua, mas também um conhecimento ligado geralmente ao gênero. A estrutura da narração de uma história é independente do

13 Mas os professores também encontram formas criativas de materiais que possibilitam o uso das duas línguas, como p.e. na alfabetizaçáo. Para exemplos de materiais usados na Holzhausenschule veja Budach (2011). 
repertório do narrador, mas a produção de cada elemento nutre-se dos conhecimentos específicos de língua aos quais o indivíduo tem acesso neste momento. Neste processo de montagem de repertório, a imersão recíproca age em dois níveis. Os alunos aprendem a diferenciar entre os registros, um recurso que vai além da língua alemã ou italiana e que também vale para outras disciplinas. Ao mesmo tempo, a quantidade e qualidade de contato com as duas línguas parceiras da imersão recíproca possibilitam um desenvolvimento de estruturas complexas e construçôes concretas nas duas línguas. $\mathrm{O}$ input linguístico do ensino tradicional de língua estrangeira não chega a este nível, porque os alunos de imersão recíproca não aprendem só formas linguísticas, mas constroem conhecimento técnico nas duas línguas parceiras. Uma vez aprendido como escrever uma história em alemão, este conhecimento pode ser aproveitado nas aulas de italiano, dando ênfase à aprendizagem das formas linguísticas adequadas. Para ver a montagem de repertório bi-/plurilíngue num exemplo concreto, vamos discutir dois exemplos da aluna Zara. As frases introdutórias escritas pela aluna no terceiro (linhas 20,21) e no quarto ano (linhas 39, 40) mostrarão o desenvolvimento no seu registro formal. Como base para cada texto escrito serve uma outra história em quadrinhos de "pai e filho" (al. Vater und Sohn).

3o ano

(20) Un uomo adetto che il bambino andarano

(21) deve leggere i libri. $4^{\circ}$ ano

(39) Una volta il padre et il figlio (40) con la barca in giro.

Uma comparação destas duas frases do terceiro para o quarto ano não permite só a observação do crescimento do registro formal, mas também das estruturas específicas da narração. Enquanto Zara começa o texto do terceiro ano diretamente com a ação dos personagens, no quarto ano a aluna usa uma fórmula introdutória "una volta" (pt. uma vez) e localiza os personagens em um certo espaço de ação ("andarono con la barca in giro", pt. deram uma volta no barco). Além do desenvolvimento na estrutura, encontra-se uma nomeação mais adequada para os personagens. No terceiro ano, a aluna escreve simplesmente "Un uomo" (pt. um homem) e "il bambino" (pt. a criança); no quarto ano ela recorre à tradução dos nomes usados em alemão: "il padre" (al. der Vater, pt. o pai) e "il figlio" (al. der Sohn, pt. o filho). Os tempos de narração 
também servem para mostrar o desenvolvimento da aluna. No terceiro ano, a menina usa o passato prossimo ("adetto" em it. ha detto vs. passato remoto de it. dire: disse); no quarto ano ela já sabe da necessidade do uso do passato remoto como passado típico de narração ("andarono" vs. passato prossimo de it. andare: è andato). Estes três níveis de análise demonstram mais do que um desenvolvimento em relação à diferenciação dos registros. A aluna precisa também conhecer estas formas reais em italiano: a forma do verbo em passato remoto é um conhecimento específico desconhecido por crianças que não têm bastante contato com a língua alvo na família ou na escola ${ }^{14}$.

\section{Conclusão}

Retomando a questão inicial, a resposta deve ser: sim, a imersão recíproca é um método de ensino/aprendizagem para comunidades bi-/plurilíngues. A partir deste método, podem ser aproveitados e valorizados tanto os recursos linguísticos quanto os culturais dos próprios alunos, indiferentemente da origem dos falantes de uma língua minoritária ou majoritária. A base destes mesmos recursos é a imersão recíproca, desenvolvendo o repertório bi-/plurilíngue do aluno, incluindo o registro formal das duas línguas parceiras. Desta forma, línguas não precisam ser vistas como concorrentes, nem no sentido econômico, nem como recurso linguístico dentro do repertório bi-/plurilíngue.

A prática demonstrou que, mesmo havendo desafios na distribuição de conteúdo em diferentes línguas durante as aulas e nas competências heterogêneas dos alunos, todos os participantes usufruem do processo de aprendizagem.

A imersão recíproca é uma ótima oportunidade para comunidades bi-/ plurilíngues, porque ela ajuda a igualar o status das línguas participantes e, da mesma forma, abre espaço para os falantes da língua minoritária ao sistema majoritário. Da parte dos falantes da língua majoritária, as vantagens encontram-se na aprendizagem de uma outra língua, melhorando as próprias chances no mercado de trabalho, ou, na perspectiva linguística, nutrindo as competências cognitivas. Ao nível social, a imersão recíproca consegue aproximar dois grupos linguístico-culturais, um alvo importante para as sociedades cada vez mais plurilíngues e pluriculturais.

14 Para uma análise detalhada do desenvolvimento de repertório de seis alunos no mesmo projeto bilíngue ítalo-alemão, veja Streb (2015). 


\section{Refêrencias}

BLOMMAERT, Jan; BACKUS, Ad. Repertoires revisited: 'Knowing language' in Superdiversity. Urban Language \& Literacies (Paper 67), 2011. http://www.kcl.ac.uk/sspp/departments/education/research/ldc/publications/ workingpapers/67.pdf, 10/01/2015.

BUDACH, Gabriele. Lesen und Schreiben Lernen in zwei Sprachen. Szenen aus der Praxis eines bilingualen, italienisch-deutschen Grundschulprojekts. (conteúdo acessível em quatro línguas: alemão, francês, inglês e italiano.): Media Design: Christoph P. Nick. C-Studios-Medienkreation, 2011.

BUDACH, Gabriele; ERFURT, Jürgen; KUNKEL, Melanie. Zweisprachig lehren und lernen. Begehung eines Forschungs- und Praxisfelds. BUDACH, Gabriele; ERFURT, Jürgen; KUNKEL, Melanie (eds.). Écoles plurilingue multilingual schools: Konzepte, Institutionen und Akteure. Internationale Perspektiven. Frankfurt am Main [u.a.]: Lang, 2008, p. 7-54.

GARCÍA, Ofelia (): Bilingual Education in the $21^{\text {st }}$ Century. A Global Perspective. Malden, Mass.: Wiley-Blackwell, 2009a.

GARCÍA, Ofelia. Education, Multilingualism and Translanguaging in the 21 st Century. SKUTNABB-KANGAS, Tove (ed.): Social justice through multilingual education. Bristol [u.a.]: Multilingual Matters, 2009b, p. 140-158.

GROSJEAN, François. Processing mixed language: issues, findings, and models. WEI, Li et al. (ed.): The bilingualism reader. London [u.a.]: Routledge, 2000, p. 443-469.

HELLER, Monica. Linguistic Minorities and Modernity. A sociolinguistic ethnography. London: Longmen, 1999.

HÉLOT, Christine. Du bilinguisme en famille au plurilinguisme à l'école. Paris: L'Harmattan, 2007.

MAAS, Utz. Sprache und Sprachen in der Migration im Einwanderungsland Deutschland. IMIS-Beiträge (26), 2005, p. 89-133.

MAAS, Utz. Sprache und Sprachen in der Migrationsgesellschaft. Die schriftkulturelle Dimension. Göttingen: V \& R Unipress, 2008.

MAAS, Utz. Literat und orat. Grundbegriffe der Analyse geschriebener und gesprochener Sprache. MAAS, Utz (ed.): Orat und literat. (Grazer Linguistische Studien (GLS), 73), 2010, p. 21-150.

PÉREZ, Bertha. Becoming biliterate: a study of two-way bilingual immersion education. Mahwah, New Jersey [u.a.]: Laurence Erlbaum Associates, 2004. 
POTOWSKI, Kim. Language and Identity in a Dual Immersion School. Clevedon [u.a.]: Multilingual Matters, 2007.

RONJAT, Jules. Le développement du langage observé chez un enfant bilingue. Hg. v. Pierre Escudé. Frankfurt am Main [u.a.]: Lang, 2014 (1913).

STREB, Reseda. Ausbau mehrsprachiger Repertoires im Two-Way-ImmersionKontext. Eine ethnographisch-linguistische Langzeituntersuchung in einer deutschitalienischen Grundschulklasse. PhD thesis. Goethe-Universität Frankfurt/M., Fachbereich 10, 2 vols. (to be published by Peter Lang winter 2016).

STREB, Reseda. Una bella donna sag ich einfach - Prozesse und Strategien im billingualen Schriftsprachenerwerb. ERFURT, Jürgen; LEICHSERING, Tatjana; STREB, Reseda (Eds.): Mehrsprachigkeit und Mehrschriftigkeit. Sprachliches Handeln in der Schule. Duisburg: Universitätsverl. Rhein-Ruhr (Osnabrücker Beiträge zur Sprachtheorie (OBST), 83), 2013, p. 151-172.

\title{
TWO-WAY IMMERSION - A TEACHING/LEARNING METHOD FOR BI-/PLURILINGUAL COMMUNITIES?
}

\begin{abstract}
:
Two-way Immersion is a very significant educational method for bi-/plurilingual communities, because it concentrates on equalty of both partner languages and cultures. How does this method works in practice? What are the challenges and advantages for the language learning process? These are the questions to be discussed in the present article.
\end{abstract}

KEYWORDS: Bi-/plurilingual teaching and learning; bi-/plurilingual repertoire; Two-way Immersion.

Recebido em: 31/05/2016 Aprovado em: 18/10/2016 